\title{
SPECIFIČNO PRILAGOĐAVANJE TRENINGA MLADOG BACAČA DISKA KAO USLOV POSTIZANJA VRHUNSKE FORME
}

\author{
Mensur Vrcić ${ }^{1}$, Ratko Pavlović ${ }^{2}$, Sid Solaković ${ }^{3}$, Erol Kovačević ${ }^{1}$ i Ensar Abazović ${ }^{4}$ \\ ${ }^{1}$ Fakultet sporta i tjelesnog odgoja Univerziteta u Sarajevu, Bosna i Hercegovina \\ ${ }^{2}$ Fakultet fizičkog vaspitanja i sporta Univeziteta u Istočnom Sarajevu, Bosna i Hercegovina \\ ${ }^{3}$ Klinika za vaskularnu hirurgiju Kliničkog centra u Sarajevu, Bosna i Hercegovina \\ ${ }^{4}$ Kineziološki fakultet, Sveučilište u Splitu, Hrvatska
}

\section{Stručni članak}

\section{SAŽETAK}

Cilj ovog rada je da se prikaže jedan model specifičnog prilagođavanja bacača diska na treningu kao i najvažnije karakteristike postizanja vrhunske forme. Uzeti su najvažniji aspekti u programu treninga sa kojim je bacač napravio vidan napredak u sezoni. Napredak se ogleda u rezultatu 58,34 m (2016. godine) u odnosu na 47,72 m (2015. godine), sa diskom od 1,5 kg, kojim se baca u kategoriji U18, što predstavlja razliku od 10,62 m. Rezultat je postignut na Prvenstvu Evrope u atletici u kategoriji mlađih juniora. Postignuti rezultat je ujedno i lični rekord, a postignut je u planirano vrijeme na finalu Prvenstva Evrope.

Ključne riječi: bacanje diska, vrhunska forma, program treninga

\section{UVOD}

Brzina napretka rezultata $\mathrm{u}$ atletskim bacanjima je uslovljena primjenom naučnih istraživanja. Postizanje superiorne sportske izvedbe direktan je rezultat prilagođavanja sportiste na različite tipove i metode treninga (Bompa, 2001). U takmičarskoj fazi, tačnije na najvažnijem takmičenju, sportista treba da postigne najbolji rezultat, ali to zahtijeva čitav niz sekvencionalnih radnji kumulativnog toka kako bi dostigli maksimalnu sportsku izvedbu na najznačajnijem takmičenju u godini. U ovom važnom razdoblju završne faze razvoja dijete prelazi iz dječijeg razdoblja u fazu odrasle osobe (Andrijašević 2010). Bacanje diska je atletska disciplina u kojoj takmičari imaju dug takmičarski vijek. Primjer uspješne i duge karijere je američki bacač diska 
Al Oerter, koji je u 43. godini života bacio 69,46 m. Ako se želi da bacač u dugom vremenskom periodu održava visok nivo rezultata, potrebno je da se napravi kvalitetna i temeljita priprema. Nisu rijetki slučajevi da bacači naprave kao juniori dobre rezultate i da kasnije ne dostignu ni približno vrijedne rezultate u odnosu na raniji period. U tom slučaju vjerovatno je da su neke "stepenice preskočene" u dugoročnom planiranju i programiranju i prerano je započeto sa treningom koji je namijenjen odraslim sportistima - seniorima (rana specijalizacija). Održavanje visokog nivoa opšte fizičke pripreme omogućuje bolju specijalizaciju u kasnijim fazama. Naravno, mora se uzeti u obzir savremena tendencija sniženja dobi sportskog sazrijevanja. U ovom radu su korišteni neki od parametara treninga bacača diska ispitanika, koji je u prvoj godini (od dvije) u kategoriji U18 osvojio četvrto mjesto na Prvenstvu Evrope u atletici u Tbilisiju (Gruzija), sa rezultatom 58,34 m, inače reprezentativac Bosne i Hercegovine u pionirskom i mlađem juniorskom uzrastu u disciplinama bacanje diska i bacanje kugle.

\section{DISKUSIJA}

U prethodnoj godini najbolji rezultat u bacanju diska od $1,5 \mathrm{~kg}$ bio je $47,72 \mathrm{~m}$ i postignut je na Balkanskim igrama u atletici za mlađe juniore. Najbolji rezultat u ovoj sezoni (2016), koji je ujedno i lični rekord, iznosi $58,34 \mathrm{~m}$. Na polufinalnom takmičenju postigao je rezultat od 57,14 m i lični rekord (do tad je lični rezultat bio 56,04 m, postignut u Splitu na Otvorenom bacačkom prvenstvu Hrvatske). Ukupni napredak u sezoni od 10,62 m je pretpostavka za uspješan nastup (osvajanje medalje) u narednoj godini na Svjetskom prvenstvu u Keniji. Važan atribut vrhunca izvedbe sportiste je sposobnost tolerancije različitih nivoa frustracije, koji se pojavljuju prije, tokom i poslije takmičenja (Bowerman, Freeman i Gambeta, 2012). Planirani vrhunac forme je bio tempiran za Evropsko prvenstvo u Tbilisiju (Gruzija), gdje je i postignut, a za narednu sezonu je to Svjetsko prvenstvo u Najrobiju (Kenija). Obzirom da su ispitanici u ovoj sezoni bili takmičari stariji jednu godinu (misli se na trojicu prvoplasiranih), uzevši u obzir njegove vršnjake i nadolazeće rezultate, realna su očekivanja da na Svjetskom prvenstvu osvoji jednu od medalja.

Obzirom da je sportista ušao u fazu specijalizacije i može podnijeti veće zahtjeve treninga i takmičenja, pažljivo su uvrštene vježbe čiji je cilj razvoj vrhunske izvedbe (Bompa, 2001). Prilikom planiranja trenažnog procesa, što je i osnovni zadatak trenera, posebna pažnja je posvećena tehnici bacanja diska i vježbanju primarnih pokretača koje sportaši koriste tokom 
izvedbe tehničkih disciplina. Ishrana je zasnovana na maksimalnom korištenju prirodnih potencijala i dolaženja do hranjivih materija što je više moguće iz prirodnih izvora.

Analizom rezultata testiranja motoričkih sposobnosti u 2015, prije početka sezone, kao i analizom dotadašnjih teninga ustanovljeno je da je bacač diska u svom dosadašnjem razvojnom periodu imao nizak nivo u nekim opštim i specifičnim motoričkim sposobnostima.

Tabela br. 1. Rezultati motoričkih testova u 2015. i 2016. godini sa planom za 2017.

\begin{tabular}{|c|c|c|c|c|c|}
\hline Test & $\mathbf{2 0 1 5 .}$ & $\mathbf{2 0 1 6 .}$ & $\begin{array}{c}\text { Razlika } \\
\mathbf{2 0 1 6} / \mathbf{1 7 .}\end{array}$ & Plan za 2017. & $\begin{array}{c}\text { Vrhunski bacači diska } \\
\text { senori } \\
\text { (modalne } \\
\text { karakteristike) }\end{array}$ \\
\hline Trzaj u polučučanj (snagom) & $65 \mathrm{~kg}$ & $80 . \mathrm{kg}$ & $15 . \mathrm{kg}$ & $95 . \mathrm{kg}$ & $135-140 . \mathrm{kg}$ \\
\hline Duboki čučanj & $135 \mathrm{~kg}$ & $160 . \mathrm{kg}$ & $25 . \mathrm{kg}$ & $180 . \mathrm{kg}$ & $270-280 . \mathrm{kg}$ \\
\hline Potisak na ravnoj klupi & $110 \mathrm{~kg}$ & $120 . \mathrm{kg}$ & $10 . \mathrm{kg}$ & $140 . \mathrm{kg}$ & $240-260 . \mathrm{kg}$ \\
\hline Troskok s mjesta sunožno & $635 \mathrm{~cm}$ & $705 . \mathrm{cm}$ & $70 . \mathrm{cm}$ & $810 . \mathrm{cm}$ & $10,00-10,50$ \\
\hline 30 m sprint - visoki start & $4,58 \mathrm{~s}$ & $4,33 . \mathrm{s}$ & $-0,25 . \mathrm{s}$ & $4,10 . \mathrm{s}$ & \\
\hline Kugla 3 kg s mjesta kao disk & $21,45 \mathrm{~m}$ & $26,60 . \mathrm{m}$ & $5,15 . \mathrm{m}$ & $32,50 . \mathrm{m}$ & $45 \mathrm{~m}$ \\
\hline Kugla 5 kg preko glave & 13,67 & $17,10 . \mathrm{m}$ & $3,43 . \mathrm{m}$ & $21,00 . \mathrm{m}$ & $21-22 \mathrm{~m}(7,26 \mathrm{~kg})$ \\
\hline Disk 1,5 kg bacanje iz mjesta & $37,20 . \mathrm{m}$ & $46,55 . \mathrm{m}$ & $9,35 . \mathrm{m}$ & $53,50 . \mathrm{m}$ & \\
\hline Disk 2 kg iz okreta & $40,03 . \mathrm{m}$ & $48,28 . \mathrm{m}$ & $8,25 . \mathrm{m}$ & $54,00 . \mathrm{m}$ & $68-72 \mathrm{~m}$ \\
\hline Disk 1,5 kg iz okreta & $\mathbf{4 7 , 7 2 . m}$ & $\mathbf{5 8 , 3 4 . m}$ & $\mathbf{1 0 , 6 2 . m}$ & $\mathbf{6 5 , 0 0 . m}$ & \\
\hline
\end{tabular}

Dijagram 1. Rezultati testova za procjenu opšte snage u 2015. i 2016. godini sa planom za 2017.

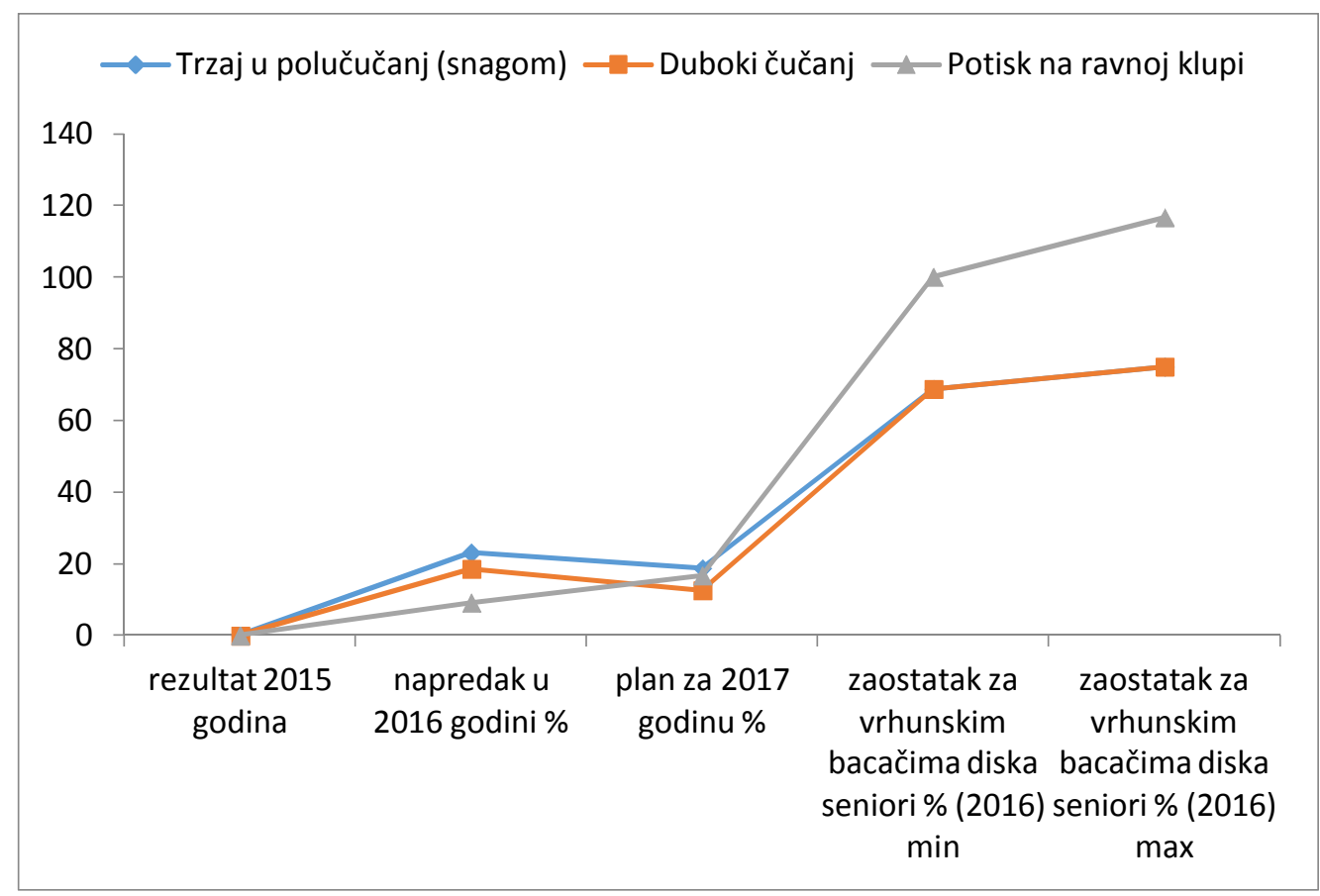


Dijagram 2. Rezultati testova za procjenu eksplozivne snage u 2015. i 2016. godini sa planom za 2017.

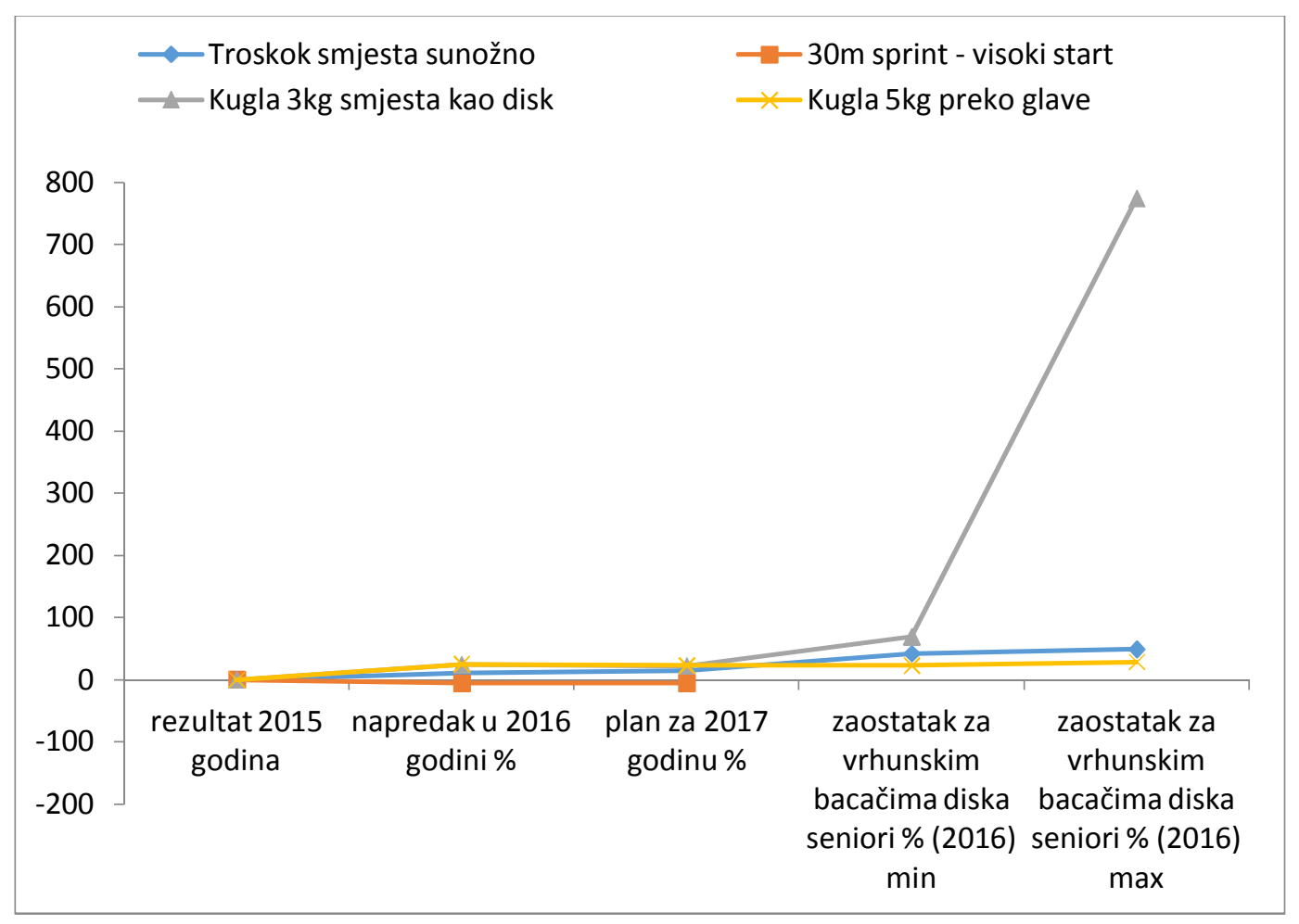

Dijagram 3. Rezultat postignut u bacanju diska (pokazatelj sportske forme) u 2015. i 2016. godini sa planom za 2017.

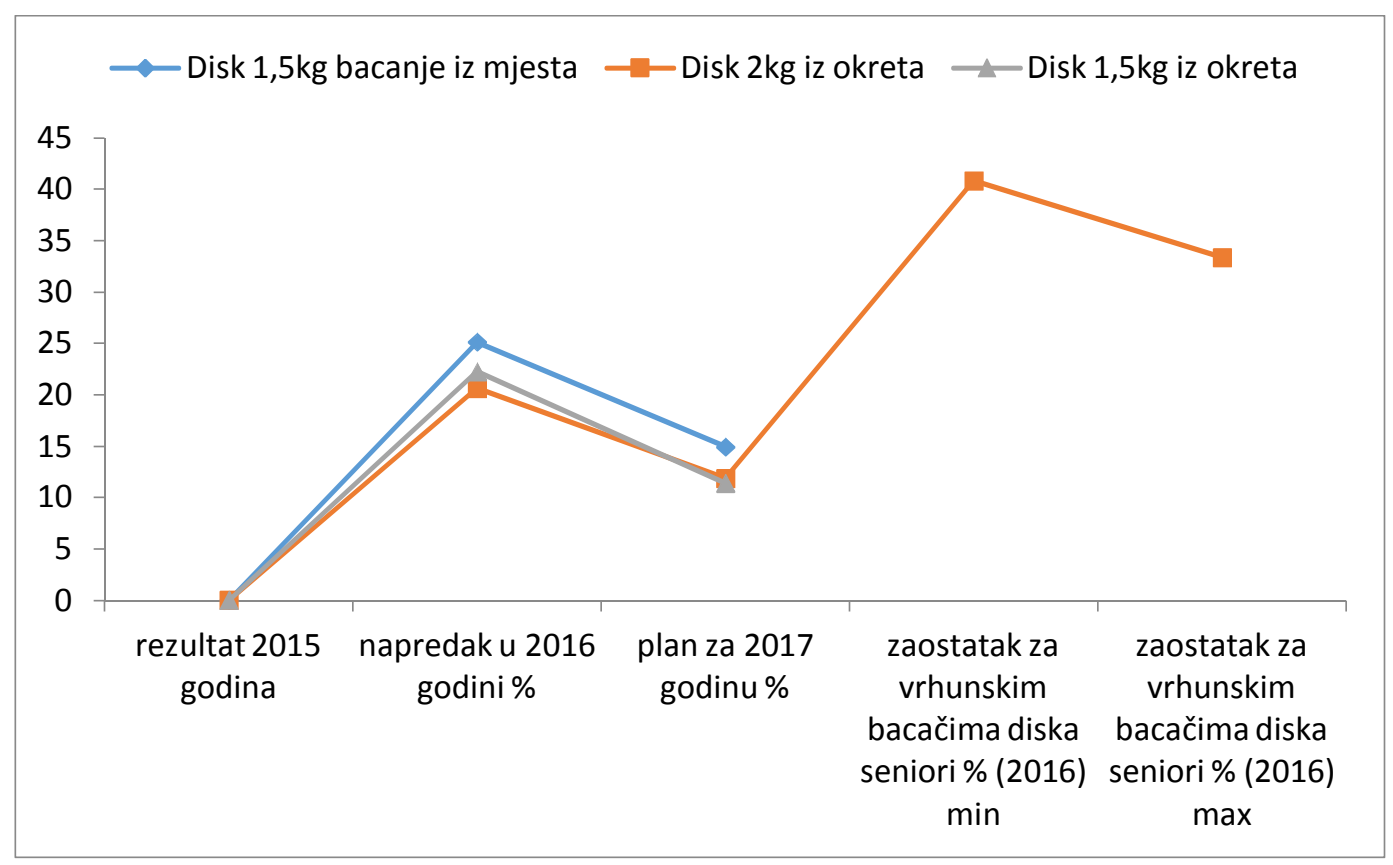


Deficiti u rezultatima testova motoričkih sposobnosti (troskok s mjesta, sprint $30 \mathrm{~m}$ ) često limitiraju tehničku izvedbu. U ovom periodu bi sportaši trebali da imaju visok nivo tehničke izvedbe na kojoj treba insistirati ukoliko se želi da se maksimalno iskoristime motoričke sposobnosti. Dobar pokazatelj visokog nivoa tehnike je razlika između bacanja sprave iz mjesta i okreta. Što je veća razlika to bacač okretom dolazi u poziciju da ostvari veću brzinu kod izbačaja. Kategorija bacača diska U18 baca disk težine 1,5 kg. Na treninzima se, osim bacanja težinski propisane sprave od 1,5 kg koriste i lakše $(1 \mathrm{~kg}, 1,25 \mathrm{~kg})$ i teže sprave $(1,75 \mathrm{~kg}, 2 \mathrm{~kg})$. Kreativnost i umijeće trenera ogleda se upravo u pravilnoj distribuciji bacanja sprava različite težine tokom cijele godine, kao i planiranjem broja i dužine.

U takmičarskom periodu je:

- smanjivan ukupni broj opštih bacanja (bacanja na razne načine, kao što je bacanje kugle ispred, preko sebe, u vis i sl.), a povećao se broj hitaca iz poluokreta i okreta;

- intenzitet bacanja je talasasto rastao do posljednjih 10 dana pred takmičenje kada se sa 9095\% intenziteta smanjio na 70-80\%;

- u treninzima sa tegovima su u posljednjih mjesec dana najviše bile zastupljene specifične vježbe za bacače diska (razvlačenja ispruženim rukama na ravnoj klupi, zasuci sa teretom na leđima, otkloni sa pločom u ruci u stranu). Najviše su korištene vježbe eksplozivnog karaktera (trzaj, nabačaj, skok iz polučučnja, skok iz pretklona) tako što je start bio od koljena i pola natkoljenice uz minimalnu fiksaciju tega nakon podizanja;

- posljednji mjesec dana izbacilo se bacanje diska od $2 \mathrm{~kg}$, dok je uvršteno bacanje lakše sprave $(1,25 \mathrm{~kg})$ dvaput sedmično, a $1,75 \mathrm{~kg}$ jedanput sedmično. Takmičarsku spravu je bacao dvaput sedmično;

- povećan je broj vježbi rastezanja muskulature koja neposredno sudjeluje u bacanju.

Kategorija U18 je kategorija mlađih juniora u kojoj nastupaju takmičari uzrasta 16 i 17 godina.

Trenažni proces sve više poprima karakteristike treninga seniora, ali ipak se moraju poštivati specifičnosti mladog organizma kako ne bi došlo kasnije do stagnacije rezultata. Tokom specijalizacije, kao faze sportskog razvoja, naglasak je stavljen na vježbe izabranog sporta. Temelji postavljeni tokom specijalizacije bolje će omogućiti dobru izvedbu tokom stupnja visoke izvedbe (Bompa, 2001). 


\section{ZAKLJUČAK}

Analizom postignutih rezultata u 2015. i 2016. godini može se konstatovati da je došlo do značajnog napretka u rezultatima u bacanju diska. Rezultati su ostvareni na najvažnijem takmičenju u sezoni zahvaljujući optimalnom doziranju intenziteta i volumena u toku sezone, kao i specifičnoj adaptaciji za planiranu sportsku formu. Ostavljeno je dovoljno prostora za daljnje napredovanje $\mathrm{u}$ rezultatima tako što nisu iskorišteni mnogi kondicioni kapaciteti $\mathrm{u}$ trenažnom procesu. Veliki broj parametara ne zadovoljava modalne karakteristike u nekim testovima što je zadatak da se u narednom periodu poprave lošije performanse. Preduvjet za daljnje napredovanje u bacanju je kontinuirano usavršavanje tehnike i podizanje općih i specifičnih sposobnosti. Krajem "sportskog školovanja" mnogi sportaši koji su razvili solidne temelje i žele postići vrhunski rezultat u određenom sportu bit će u stanju specijalizirati ga (Bompa, 2005).

\section{LITERATURA}

Andrijašević, M. (2010). Kineziološka rekracija. Zagreb, RH: Kineziološki fakultet Sveučilišta u Zagrebu.

Bowerman, W. J., Freeman, W., H., \& Gambetta., V. (2012). Atletika - periodizacija, tehnika i program treninga za sve discipline. Zagreb, RH: Gopal.

Bompa, T. (2005). Cjelokupan trening za mlade pobjednike. Zagreb RH: Gopal.

Bompa, T. (2001). Periodizacija: teorija $i$ metodologija treninga. Zagreb RH: Hrvatski košarkaški savez.

Primljeno: 11.05.2017.

Odobreno: 20.06.2017.

Korespodencija:

Prof. dr Mensur Vrcić

Fakultet sporta i tjelesnog odgoja

Univerzitet u Sarajevu

Patriotske lige 41,

Sarajevo 71 000,

Bosna i Hercegovina

Tel: +38733668768

Fax: +38733211537

mvrcic@fasto.unsa.ba 